\title{
СОВЕРШЕНСТВОВАНИЕ МОТИВАЦИИ ПЕРСОНАЛА ПОСРЕДСТВОМ ВЛОЖЕНИЙ В ЧЕЛОВЕЧЕСКИЙ КАПИТАЛ (РОССИЙСКАЯ СПЕЦИФИКА)
}

\author{
(c) 2020 Шаркевич Дарья Николаевна \\ студент \\ Самарский государственный экономический университет, Россия, Самара \\ () 2020 Полынова Людмила Викторовна \\ кандидат экономических наук, доцент \\ Самарский государственный экономический университет, Россия, Самара
}

Капиталовложения в человека в государствах с развитой экономикой увеличиваются с каждым годом всё более стремительными темпами, нежели инвестиции в материальные и технические ресурсы организаций, при этом уровень итоговых затрат на социальные сферы, такие как медицина, например, в несколько раз превосходят объем инвестиций в область производства. В соответствии с некоторыми оценками, продуктивность и отдача от персонала, имеющего высшее образование, варьируется от 8 до 12\%, а уровень средней заработной платы от использования труда таких работников обычно составляет не более 5-6\%. В особенности это заметно на примере роста национального богатства, где инвестиции в образование дают прирост порядка 25-35\% [7].

Ключевые слова: человеческий капитал, мотивация, стимулирование, национальное богатство, инвестиции, затраты, кадры.

Исторически сложилось так, что различные направления развития теоретических основ понятия человеческого капитала разноплановы и нередко дискуссионны. В рыночной экономике более правильно использовать трактовку человеческого капитала как инструмента, который охватывает социально-экономическую эффективность производства на микроуровне и социально-экономического инструмента в широком смысле на макроуровне. Ряд зарубежных исследователей рассматривает «человеческий капитал» в качестве инструмента экономического роста. В содержание понятия «человеческий капитал» зарубежные исследователи включают знания, навыки, которые формируют добавленную стоимость продукции или услуги [Maslow A. N. Motivation and Personality: Harper and Row, 1970. 84 p.].

Современный термин «людские ресурсы» ближе по смыслу к термину, затрагивающему понятие «человеческого капитала». При этом в отличие от понятия «трудовые ресурсы», он имеет несколько иной смысл. Выражается его содержание в передовых формах организации труда, накоплении опыта, разработках в сфере науки, управления и маркетинга.

Предпринято большое количество попыток отыскать единый универсальный способ расчета стоимости человеческого актива; так прово- дились исследования всех влияющих факторов оценки - деловые, интеллектуальные качества, приобретенные навыки, здоровье, культурный и духовный уровень и т.д., были также представлены различные варианты формул расчетов и методов оценки. Все эти усилия обоснованы потребностью организаций в информационной базе показателей активов, для подготовки инвестиционных мероприятий и бизнес планирования. В этом случае человеческий капитал измеряется как дисконтированная величина заработка в течение всей жизни человека, то есть с точки зрения экономических выгод рабочей силы

Термины «мотивация» и «стимулирование», по мнению многих исследователей, являются близкими по смыслу понятиями. Однако, например, понятие «стимул» применяется только в тех случаях, когда речь идет о материальном или моральном поощрении работника, а вот понятие «мотив» затрагивает все стороны поведения сотрудника [6]. От эффективности функционирования систем мотивации непосредственно зависят и результаты деятельности фирмы, в особенности это касается случаев, когда на предприятии внедряются новые технологии и мероприятий научно-технического прогресса [5].

Существующие на данный момент определения ученых не имеют особой разницы. Поэтому 
затраты на мотивацию персонала, как правило, рассматриваются в качестве суммы затрат, связанных непосредственно с их содержанием, развитием.

Как утверждает А.Я.Кибанов, затраты на мотивацию персонала субъекта хозяйствования необходимо рассматривать в качестве интегрированного показателя, который в свою очередь определяет сумму издержек, взаимосвязанных с привлечением и мотивацией персонала, а также с улучшением условий труда сотрудников хозяйствующего субъекта [2].

Ю.Н.Павлючук придерживается мнения, что под издержками на стимулирование персонала целесообразно понимать часть стоимости, которая образует фонд жизненных средств, требуемых для воспроизводства трудовых ресурсов в рамках определенных социальноэкономических условий. Подобное определение скорее раскрывает издержки на персонал как макроэкономическую категорию, поскольку обращено к области общественного воспроизводства [1].

Почти половину всего совокупного богатства России составляет человеческий капитал - 46\%. Такие данные приводит Всемирный банк в специальном докладе «Насколько богата Россия?». Это относительно много для сырьевой державы, до среднего показателя развитых стран в 70\% еще очень далеко. Чтобы догнать развитые экономики по этому показателю, стране потребуется от 50 до 100 лет при нынешних темпах, подсчитали аналитики.

Согласно проведенным исследованиям, к 2030 году в мире возникнет глобальный дефицит человеческих кадров, приблизительно 85 млн. чел., что эквивалентно населению Германии. На текущий момент малый и средний бизнес на постоянной основе испытывает определенную нехватку высококвалифицированного персонала. Главной мерой решения данной проблемы являются инвестиции в человеческий капитал. Это способно, во-первых, повысить уровень жизни общества в целом, во-вторых, предотвратить замедление роста экономики. По данным Всемирного банка в мире около $55 \%$ рожденных детей будут продуктивны лишь на половину, наилучшие условия для этого - уровень здоровья и образование.

По рекомендациям Всемирного банка, в России целесообразно проводить политику, последовательно направленную на увеличение доли человеческого капитала в структуре национального богатства и на повышение отдачи от накопленного человеческого капитала. В частности, рекомендуют:

- Наращивать потенциал университетского образования

- Повышать качество российской системы профессионально-технического образования

- Совершенствовать soft skills - навыки коллективного решения задач, коммуникационные компетенции и креативность

- Повышать роль первичной медикосанитарной помощи, включая диагностику, профилактику и ведение заболеваний, вместо дорогостоящего лечения, необходимого на более поздних стадиях.

Показатель человеческого капитала на душу населения в России вырос почти на 80\% с 2000 года, однако составляет лишь одну пятую от среднего показателя по Организации экономического сотрудничества и развития (около 100 тыс. \$ против 500 тыс. \$).

Экономисты МГУ, ВШЭ и РАНХиГС раскритиковали проект бюджет РФ на 2020-2022 г. за излишний оптимизм экономического прогноза, а именно, за недостаточные инвестиции в человеческий капитал. ВШЭ отмечает - бюджет консервирует сложившуюся структуру расходов при невозможности существенно увеличить производительные бюджетные расходы (на образование, здравоохранение, инфраструктурные инвестиции) даже в условиях реализации национальных проектов. В связи с этим предлагают дополнительно проанализировать риски неполной реализации нацпроектов в связи с недостаточным финансированием из федерального бюджета.

Производительные расходы всей бюджетной системы, увеличивающие человеческий капитал, в проектах Минфина до 2022 г. также существенно не растут. Доля расходов бюджетной системы на образование сократится с 3,8\% в 2020 г. до 3,6\% в 2022-м, а расходы на здравоохранение по отношению к ВВП составят 3,6\% в 2020 г. и 3,4\% B 2022-м.

Как отмечают эксперты РАНХиГС и Института Гайдара, для успешного структурного развития требуется поддержать совокупные расходы государства на уровне не ниже 35,5-36\% ВВП. «Судя по структуре расходов к 2036 г. [долгосрочный бюджетный прогноз], так и останутся недофинансированными вложениями в человека (обра- 
зование и здравоохранение)» - подчеркивают они.

ВШЭ предлагает увеличить бюджетные расходы на человеческий капитал за счёт ослабления бюджетного правила - через увеличение цены отсечения нефти. По их расчетам, увеличение цены отсечения на 5 \$ за баррель в современных условиях равносильно увеличению расходов федерального бюджета примерно на 700 млрд.руб. В 2020 г. все доходы от продажи нефти сверх цены $42,4 \$$ за баррель будут направлен в Фонд национального благосостояния (ФНБ) [9].

О необходимости увеличить инвестиции в образование и здравоохранение пишет и Финансовый университет. Это будет способствовать снижению неравенства в доходах, решению проблемы бедности, повышению социальной мобильности населения и в конечном счете «сокращению региональных диспропорций и устойчивому экономическому росту».

Крупнейшая международная компания по аутсорсингу и управлению персоналом Kelly Services ежегодно публикует на официальном сайте обзоры рынка кадровых ресурсов, за основу берут результаты опроса сотрудников различных фирм. Наглядно отображены основные факторы, мотивирующие персонал, результаты исследования Kelly Services в России в 2018 и 2019 г. отображены на рис. 1. В 2019 г. число респондентов >1000 чел., из них 52\% мужского населения, возрастной диапазон 18-25 (23\%), 26-33(40\%), 35-45 (29\%), более 45 (8\%), более $64 \%$ респондентов имело высшее образование, 14\% несколько высших, 10\% незаконченное выс- шее и 9\% среднее. Более $74 \%$ респондентов отдают предпочтение международным компаниям и лишь $26 \%$ российским, где из них, $5 \%$ желают работать в гос. структурах (органы власти и администрации), 6\% в российских государственных компаниях 15\% в частных компания [10].

При выборе потенциального работодателя основными и решающими факторами из года в год остается заработная плата и социальный пакет сотрудника, на втором месте по значимости комфортная атмосфера, на третьем возможность карьерного роста. Если говорить о зарплате, то кандидаты отметили, что хотят получать её либо в виде $100 \%$ оклада (42\% респондентов), либо оклад и бонус в соотношении 60/40 (41\%), менее популярными вариантами оказались 50/50 (12\%) и 30/70 (5\%). Наиболее комфортная периодичность бонусов - более чем для половины соискателей (56\%) раз в квартал, еще для $29 \%$ - раз в месяц, $10 \%$ согласны получать бонусы 2 раза в год и $6 \%$ достаточно 1 раза.

Среди наиболее важных опций соц.пакета отметили дополнительное медицинское страхование (48\%), предоставление корпоративного автомобиля (24\%), корпоративные тренинги (20\%), оплата мобильной связи и возможность изучения английского языка (по 18\%). Наиболее подробно важные опции социального пакета, с точки зрения опрошенных (см. рисунок 2)

Исследование также выявило низкую мобильность сотрудников, на вопрос «Готовы ли Вы к переезду ради интересной работы?» $37 \%$ опрошенных ответили отрицательно, еще 33\% готовы переехать только заграницу, 11\% могут

Уровень оплаты труда и соц.пакет Комфортная атмосфера Офиц. оформление и "белая" зп Возможность карьерного роста Масштабные и интересные задачи Репутация компании Профессионализм коллег Возможность обучения Гибкий график Зарубежные проекты Удобное расположение офиса Отсутствие переработок

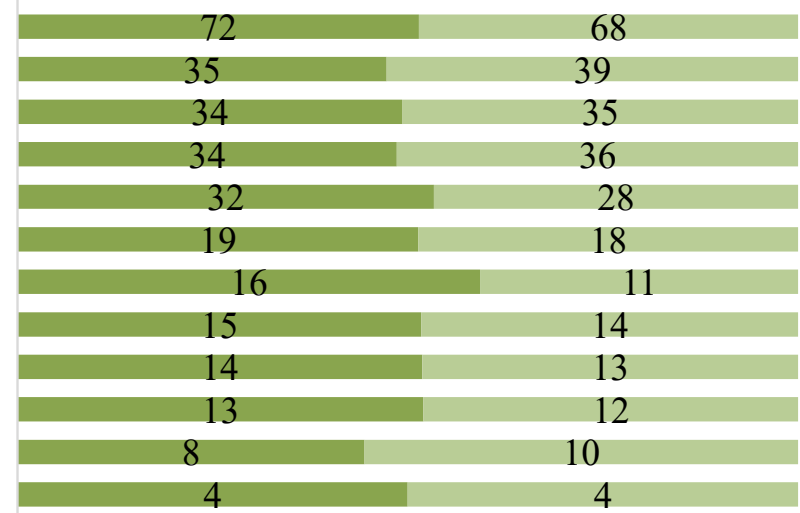

$\begin{array}{llllll}0 \% & 20 \% & 40 \% & 60 \% & 80 \% & 100 \%\end{array}$

Рuc. 1. Диаграмма факторов, мотивирующих персонал. 


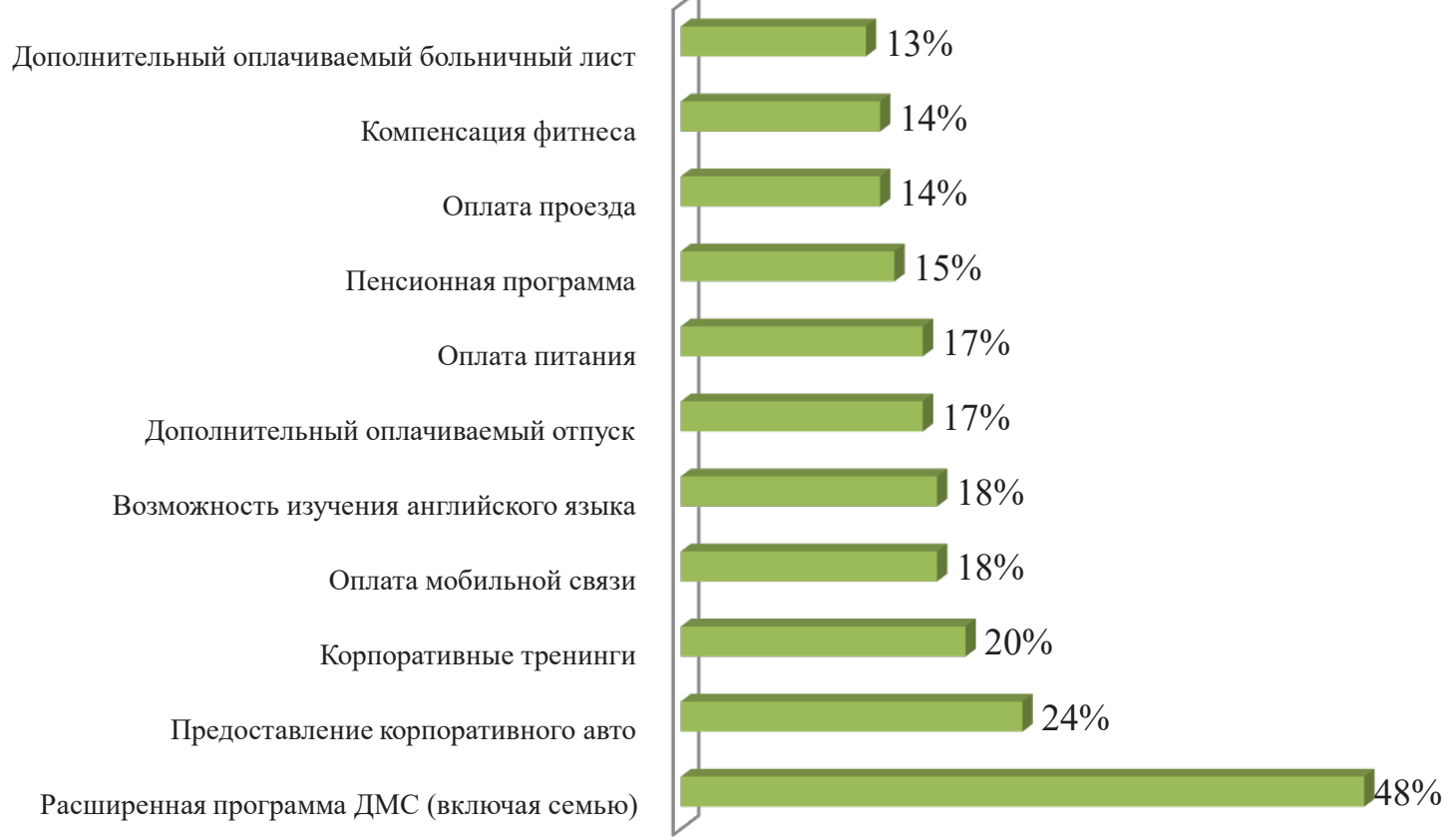

Puc. 2. Наиболее важные опции соц.пакета в РФ

отправиться из Москвы в Санкт-Петербург, 19\% готовы к переезду внутри РФ (из регионов).

А вот тренд на гибкие условия работы, активно набирает обороты на рынке труда, согласно данным опроса 80\% респондентов предпочли бы работать вне офиса, если бы у них была такая возможность, и всего $20 \%$ работу в офисе. «В настоящее время все больше сотрудников компаний задумываются о балансе работой и личной жизнью. Работа из дома позволяет экономить время на дорогу, дает возможность в тишине сосредоточиться на рабочих задачах, выйти из состояния стресса. Для крупных городов это также решение вопроса парковки автомобиля в центре город. Преимущества получают те компанииработодатели, где такая возможность есть.» комментирует Анна Шляпочникова, лидер практики Life Sciences Kelly Services CIS.

На вопрос «Что Вас не устраивает в текущей роли/направлении?» 63\% опрошенных не довольны уровнем заработной платы, 59\% отсутствием карьерного роста, 54\% рутинностью работы, $47 \%$ стилем управления, $23 \%$ регулярными переработками, 16\% отсутствием социальных гарантий, 13\% плохими взаимоотношениями в коллективе, $11 \%$ удаленностью места работы, $4 \%$ вредными производственными факторами.

Таким образом, портрет современного сотрудника следующий: выбирает работодателя по уровню заработной платы и возможностям карьерного роста, предпочитает работать вне офиса, не готов к переезду, доволен своей работой, хочет получать большую часть фиксированного оклада, может уйти туда, где интереснее и масштабные задачи.

\section{Заключение}

В связи с этим, концепция мотивации и стимулирования кадрового состава предприятия строится на том, что подход к любому отдельно взятому индивиду или группе индивидов должен подбираться в соответствии не только с потребностями, но в первую очередь с экономическими возможностями хозяйствующего субъекта.

Это приобретает высокую степень важности особенно в условиях уменьшения числа трудоспособных граждан в нашем государстве. К числу основных целей демографической политики Российской Федерации на период до 2025 г. выступает стабилизация численности страны в пределах 140-145 млн. чел. и создание соответствующих условий для ее стремительного роста к 2025 году до 148-150 млн. чел. Следовательно, численность граждан в нашем государстве в ближайшем будущем будет продолжать уменьшаться, а жесткая борьба за кадры - усиливаться. 


\section{Библиографический список}

1. Гладкова О.А. Затраты на персонал - необходимое условие стратегического управления персоналом// Российское предпринимательство 2015. № 2 .

2. иибанов А.Я., Гагаринская Г.П., Калмыкова О. Ю., Мюллер Е.В., Управление персоналом: учебное пособие Инфра-М, 2018 г.

3. Мескон М.Х., Альберт М., Хедоури Ф. Основы менеджмента - М.: Вильямс, 2015.

4. Одегов Ю.Г. Мотивация персонала: учебник / Ю.Г. Одегов, Г.Л. Руденко, С.И.Апелько, А.И.Мерко.- М.: Альфа-Пресс, 2014.

5. Полынова Л.В., Богданова С. В., Особенности мотивации творческого персонала// Известия ИСУ СГЭУ, Самаpa, 2016, № 2(14)

6. Полынова Л.В., Богданова С.В., Современная мотивация для работника и работодателя// Вестник молодых ученых. Самара, 2017, № 1(35)

7. Электронный ресурс. Мотивация. Новости и статьи от Forbs - https://www.forbes.ru/tegi/motivaciya

8. Электронный ресурс. Исследования от Hays - https://hays.ru/res/

9. Электронный ресурс. Российский медиахолдинг «РБК»- www.rbc.ru

10. Электронный ресурс. Исследования, тренды рынка труда от Kelly Services - https://www.kellyservices.ru/ru/ about-company/workfor.. 